\title{
ANATOMIA DA MADEIRA DE Toona ciliata CARACTERÍSTICAS DAS FIBRAS PARA PRODUÇÃO DE PAPEL
}

\author{
Silvana Nisgoski ${ }^{1}$, Rosilani Trianoski ${ }^{2}$, Graciela Inés Bolzon de Muniz ${ }^{1}$, Jorge Luis Monteiro de Matos ${ }^{3}$, \\ Francielli Rodrigues Ribeiro Batista ${ }^{4}$ \\ ${ }^{1}$ Eng $^{\mathrm{a}}$. Florestal, Dr ${ }^{\mathrm{a}}$., Depto. de Engenharia e Tecnologia Florestal, UFPR, Curitiba, PR, Brasil - nisgoski@ufpr.br; gbmunize@ufpr.br \\ ${ }^{2}$ Eng $^{\text {a }}$ Industrial Madeireira, M.Sc., Doutoranda em Ciências Florestais, UFPR, Curitiba, PR, Brasil - rosilani@ufpr.br \\ ${ }^{3}$ Eng. Florestal, Dr., Depto. de Engenharia e Tecnologia Florestal, UFPR, Curitiba, PR, Brasil - jmatos@ufpr.br \\ ${ }^{4}$ Acadêmica de Engenharia Industrial Madeireira, UFPR, Curitiba, PR, Brasil - franciellirb@ gmail.com
}

Recebido para publicação: 14/12/2010 - Aceito para publicação: 29/07/2011

\begin{abstract}
Resumo
A madeira de cedro-australiano, plantado no Brasil visando à produção de serrados, foi caracterizada anatomicamente, avaliando-se os elementos constituintes no sentido medula-casca, além das relações entre as dimensões das fibras, índices indicadores da qualidade da polpa celulósica a ser produzida. Foram utilizados discos retirados do diâmetro à altura do peito (DAP) de cinco árvores com 18 anos de idade. A madeira apresenta cerne e alburno distintos, anéis de crescimento distintos a olho nu, textura fina a média, com brilho e grã regular. O diâmetro tangencial dos poros e a largura dos raios aumentaram no sentido medula casca, ao contrário do número de poros por milímetro quadrado e a quantidade de raios por milímetro, que diminuíram. Os valores médios do comprimento dos elementos de vaso, das fibras, a largura da fibra e o diâmetro do lume aumentaram no sentido medula-casca, sendo que a espessura da parede teve uma pequena variação, mas não significativa estatisticamente. Os valores obtidos para os índices indicativos da qualidade da polpa celulósica não sugerem a madeira de Toona ciliata M. Roem para a produção de papel do tipo embalagem.

Palavras chave: Cedro-australiano; características anatômicas; polpa celulósica.
\end{abstract}

\begin{abstract}
Toona ciliate wood anatomy and fiber characteristics for paper production. The Australian cedar wood, planted in Brazil to aim at saw wood production, was anatomically characterized, evaluating the constituent elements variation from pith to bark, as well the relationship between fiber dimensions, index indicating the quality of cellulose produced. Were obtained discs at breast high (DBH) of five trees with 18 years old. The wood has heartwood and sapwood distinct, growth rings distinct without lens, fine to medium texture, with brightness and straight grain. Tangential diameter of vessel lumina and ray width increased from pith to bark; unlike vessels per square millimeter and rays per millimeter that decreased. The mean values of vessel element length, fiber length, fiber width, lumen diameter increased from pith to bark, and fiber wall thickness had a little variation, but not statistically significant. The obtained values for quality pulp indicative index don't suggest Toona ciliata M. Roem wood for package paper production.

Keywords: Australian cedar; anatomic characteristic; cellulose pulp.
\end{abstract}

\section{INTRODUÇÃO}

Toona ciliata M. Roem é popularmente conhecida por cedro-vermelho, toúna (LORENZI et al., 2003), cedro-australiano, cedro-de-Himalaia, indian mahogany, moulmein cedar, australian red cedar e tooni (SOLER, 2006). É uma árvore caducifólia, nativa desde a Índia e Malásia até o norte da Austrália, com tronco ereto e cilíndrico, revestido por casca suberosa de cor marrom (LORENZI et al., 2003). Apresenta crescimento mais rápido que outras espécies nativas e exóticas de alto valor (STYLES, 1972; TARNOWSKI, 2007).

A espécie fornece madeira de boa qualidade e aceitação mundial para marcenaria e construção civil, semelhante ao cedro, por isso vem sendo bastante plantada visando à produção de madeira serrada. Também pode ser empregada para arborização em parques e jardins - sendo mais apropriada para regiões

FLORESTA, Curitiba, PR, v. 41, n. 4, p. 717 - 728, out./dez. 2011. 
tropicais (LORENZI et al., 2003) -, produção de lâminas e compensados decorativos (PAIVA et al., 2007), construção de barcos (GIBBS, 2005), indústria de móveis e, de modo particular, na produção de caixas de charutos, instrumentos musicais e outras finalidades especiais (LAMPRECHT, 1990).

As características da madeira são similares ao cedro e mogno e seu cultivo pode reduzir a pressão de corte sobre as árvores nativas. A madeira é conhecida como fonte de cedrelona, enquanto as folhas, de toonacilina. Estudos com seus extratos mostram uma forte inibição da alimentação e atividade inseticida contra Hypsipyla grandella e Epilachma varivestis (OIANO NETO, 2000).

A madeira do cedro-australiano é semelhante ao mogno brasileiro (Swietenia macrophylla), tem cor vermelho-clara que escurece com o tempo, é brilhante, tem peso médio, textura moderadamente grosseira, mas uniforme, grã direita a levemente revessa e boa trabalhabilidade. Depois de seca é estável (GIBBS, 2005) e exala um agradável odor após ser processada (LAMPRECHT, 1990).

A madeira de Toona ciliata apresenta massa específica básica que varia entre $0,31 \mathrm{~g} / \mathrm{cm}^{3}$

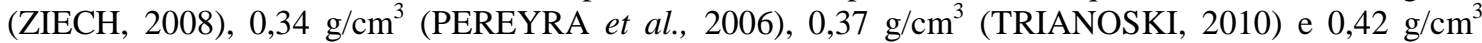
(HIDAYAT; SIMPSON, 1994), é intolerante à sombra, ocorrendo uma variação radial de $27 \%$ na sua densidade básica no oeste da Tailândia em diferentes níveis de iluminação (NOCK et al., 2009).

A Toona ciliata é uma espécie promissora para o estudo de anéis de crescimento na Austrália, pois exibe anéis anuais distintos, um requisito prévio para alta qualidade de estudos dendroclimáticos. A variabilidade na largura dos anéis de crescimento é principalmente dependente da precipitação anual (HEINRICH et al., 2009). A espécie tem três características de diagnóstico para a identificação típica de um anel de crescimento, sendo a primeira uma linha inicial de células de parênquima, a segunda uma mudança abrupta dos poucos e pequenos vasos de lenho tardio para uma linha de muitos e grandes vasos de lenho inicial, e a terceira a mudança de paredes das fibras espessas com lume pequeno para paredes finas com lume grande no lenho inicial (HEINRICH; BANKS, 2006). Anéis anuais de crescimento distintamente marcados por uma região de grandes e numerosos poros. Poros frequentemente duplos ou subdivididos, irregularmente distribuídos, poucos na madeira outonal, raios medulares finos e moderadamente largos, uniformes, curvados ao redor dos poros, resultando em grã irregular. A madeira é durável, resistente aos cupins. O carbonato de cálcio é o principal ingrediente das cinzas (GAMBLE, 1972). Estudos mostram a possibilidade da presença de falsos anéis (HEINRICH; BANKS, 2006), os quais foram afetados por queda de folhas, sombra ou seca.

As interações mecânicas entre as fibras durante a fabricação de papel surgem por meio de suas ligações (RETULAINEN; EBELING, 1993), e os parâmetros que descrevem essas ligações, junto com as propriedades intrínsecas das fibras, têm sido estudados por serem aptos a predizer as propriedades do papel (CAMPOS et al., 2000). O comportamento e a capacidade papeleira de uma fibra podem ser determinados calculando-se a relação entre as dimensões obtidas em análise microscópica (BALDI, 2001), sendo importantes para se saber de antemão o que esperar ao empregar uma determinada madeira (URIAS, 1996).

O cedro-australiano é uma espécie com grande potencial madeireiro, e poucos estudos analisam a variação da estrutura anatômica em função da variação do local dos reflorestamentos e diferentes idades. Como hipótese de trabalho, assume-se que, no sentido radial, há um aumento nas dimensões das estruturas anatômicas, o que influencia diretamente nas características tecnológicas da madeira e na possibilidade de aplicação industrial do material em diferentes idades. Nesse contexto, este trabalho teve como objetivo a caracterização anatômica da madeira de Toona ciliata aos 18 anos, plantada na região de Corupá (SC), avaliando a existência de variação dos elementos constituintes no sentido medula-casca, além das características das fibras para a fabricação de papel.

\section{MATERIAL E MÉTODOS}

As árvores utilizadas neste estudo são provenientes de um plantio experimental de propriedade da Batisttella Florestal, com aproximadamente 18 anos de idade, instalado com sementes procedentes do Instituto de Pesquisas e Estudos Florestais (IPEF) e localizado em Corupá (SC). A região de coleta está situada a uma latitude de $26^{\circ} 23^{\prime} 19,32^{\prime}$ ' Oeste e a uma longitude de $49^{\circ} 16^{\prime} 50,74^{\prime \prime}$ 'Sul, em altitude de 75 m. O clima na região é subtropical, com temperatura média entre $15^{\circ} \mathrm{C}$ e $25^{\circ} \mathrm{C}$, oscilando entre $0{ }^{\circ} \mathrm{C}$ e 35 ${ }^{\circ} \mathrm{C}$. A precipitação média anual varia de 1200 a $1600 \mathrm{~mm}$ e há ocorrência de poucas geadas por ano, sendo que elas não possuem muita intensidade. 
A amostragem seguiu a metodologia preconizada pela Comissão Panamericana de Normas Técnicas (COPANT) 458/1972, totalizando cinco árvores (COPANT, 1972). Após a derrubada foram, retirados discos na posição do diâmetro à altura do peito (DAP), sendo divididos em três partes para a caracterização anatômica: próximo à medula, intermediário e próximo à casca. A descrição macroscópica foi efetuada nos discos e baseada nos procedimentos prescritos por Muñiz e Coradin (1991). Para a descrição microscópica, foram confeccionados corpos de prova orientados nos três eixos anatômicos (transversal, longitudinal radial e longitudinal tangencial), os quais foram cozidos em água para amolecimento. Foram retiradas seções anatômicas nos três planos, com espessura de $25 \mu \mathrm{m}$, que foram coradas, desidratadas e montadas em lâminas permanentes. Para a mensuração das características individuais das fibras, foi utilizado o processo de maceração de acordo com a técnica de Franklin (1975) modificada, descrita por Kraus e Arduin (1997), utilizando-se solução de peróxido de hidrogênio e ácido acético $1: 1$, permanecendo em estufa a $60^{\circ} \mathrm{C}$ por $24 \mathrm{~h}$. O material foi então lavado com água destilada, corado com safranina e desidratado em série alcoólica ascendente, sendo montadas as lâminas permanentes. As medições dos elementos celulares seguiram as normas da IAWA (1989) e Muñiz e Coradin (1991), sendo posteriormente calculadas as relações entre as dimensões das fibras, conforme preconizam Milanez e Foelkel (1981): coeficiente de flexibilidade (CF), fração parede (FP), índice de Runkel (IR) e índice de enfeltramento (IE).

O teste de Tukey com 95\% de probabilidade foi usado para se avaliar a diferença das características médias no sentido medula-casca, além dos índices indicativos da qualidade das fibras para a produção de polpa celulósica.

\section{RESULTADOS E DISCUSSÃO}

A madeira apresenta cerne e alburno distintos, com coloração variando do castanho avermelhado ao castanho rosado, anéis de crescimento distintos a olho nu (Figura 1), textura média a fina, com brilho e grã regular.

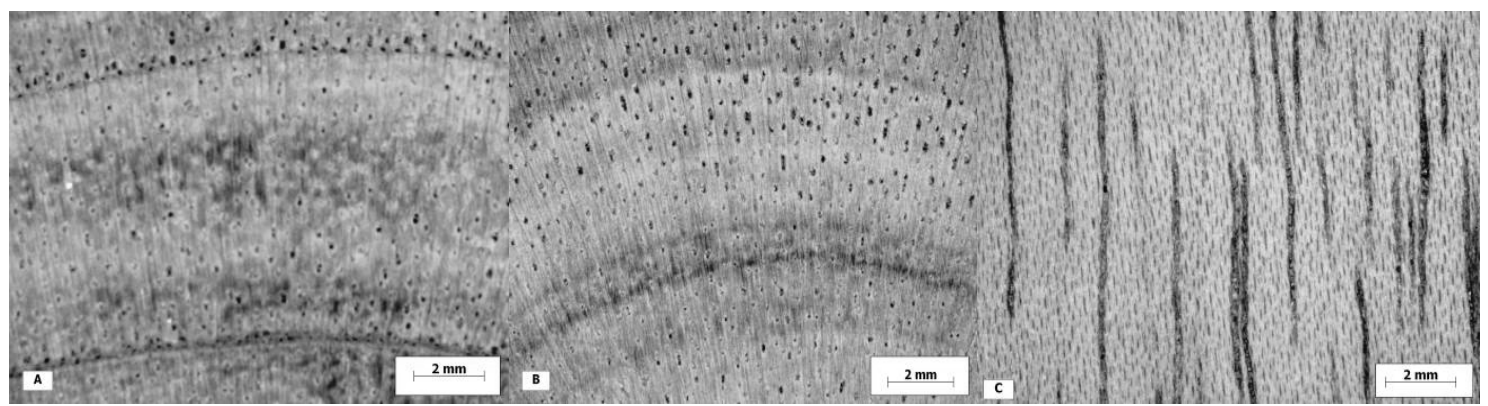

Figura 1. Aspecto macroscópico da madeira de Toona. A, B) Plano transversal - variação nos anéis de crescimento; C) Plano tangencial.

Figure 1. Macroscopic aspect from Toona wood. A, B) Transverse section - growth rings variation; C) Tangential section.

Microscopicamente, a madeira apresenta anéis de crescimento distintos, demarcados por finas linhas de parênquima marginal e diferença no tamanho dos poros (Figura 2).

Vasos: seção arredondada $(50-143,8-310 \mu \mathrm{m}, \mathrm{s}=50,46)$, porosidade em anel semiporoso, com frequência de 1-5,4-24 por $\mathrm{mm}^{2}(\mathrm{~s}=2,49)$. Solitários e geminados, múltiplos de três ocasionais (Figura 2). Elementos vasculares de 160-372,9-590 $\mu \mathrm{m}(\mathrm{s}=95,71)$, com placa de perfuração simples (Figura 3A), de dois tipos curtos e largos, estreitos e compridos, apêndices presentes (Figura 3D) em ambas as extremidades, apenas em uma ou ausentes (Figura 3C). Espessamentos helicoidais e tilos ausentes. Pontoações intervasculares areoladas alternas, pequenas (Figura 3B), não ornamentadas. Pontoações raio-vasculares e parênquimo-vasculares semelhantes às intervasculares (Figura 3E,F).

Parênquima axial em finas linhas marginais, paratraqueal vasicêntrico, unilateral e escasso presentes. Cristais tipo drusa presentes (Figura 3G,H). Cristais romboédricos eventuais. 
Raios: heterocelulares (Figura 4), com frequência de 2-6,3-14 por $\mu \mathrm{m}(\mathrm{s}=2,33)$, unisseriados (Figura 2F), com 3-12,3-29 células $(\mathrm{s}=6,32)$ e 70-263-580 $\mu \mathrm{m}(\mathrm{s}=111,44)$ de altura, multisseriados (Figura 2B), com 2-5 células de largura e 2-12,8-33 células $(\mathrm{s}=5,58)$ e 60-259,6-700 $\mu \mathrm{m}(\mathrm{s}=95,78)$ de altura. Os multisseriados predominam na região mais próxima à casca; mais perto da medula os uni $\mathrm{e}$ bisseriados (Figura 2B-2F). Raios agregados e fusionados ausentes. Cristais tipo drusa presentes.

Fibras libriformes, não septadas, pontoações simples diminutas, curtas (500-948,6-1770 $\mu \mathrm{m}$, $\mathrm{s}=218,17)$, de paredes delgadas a espessas $(3,1-6,5-15,0 \mu \mathrm{m}, \mathrm{s}=2,32)$ (Figura 4). Espessamentos helicoidais ausentes.

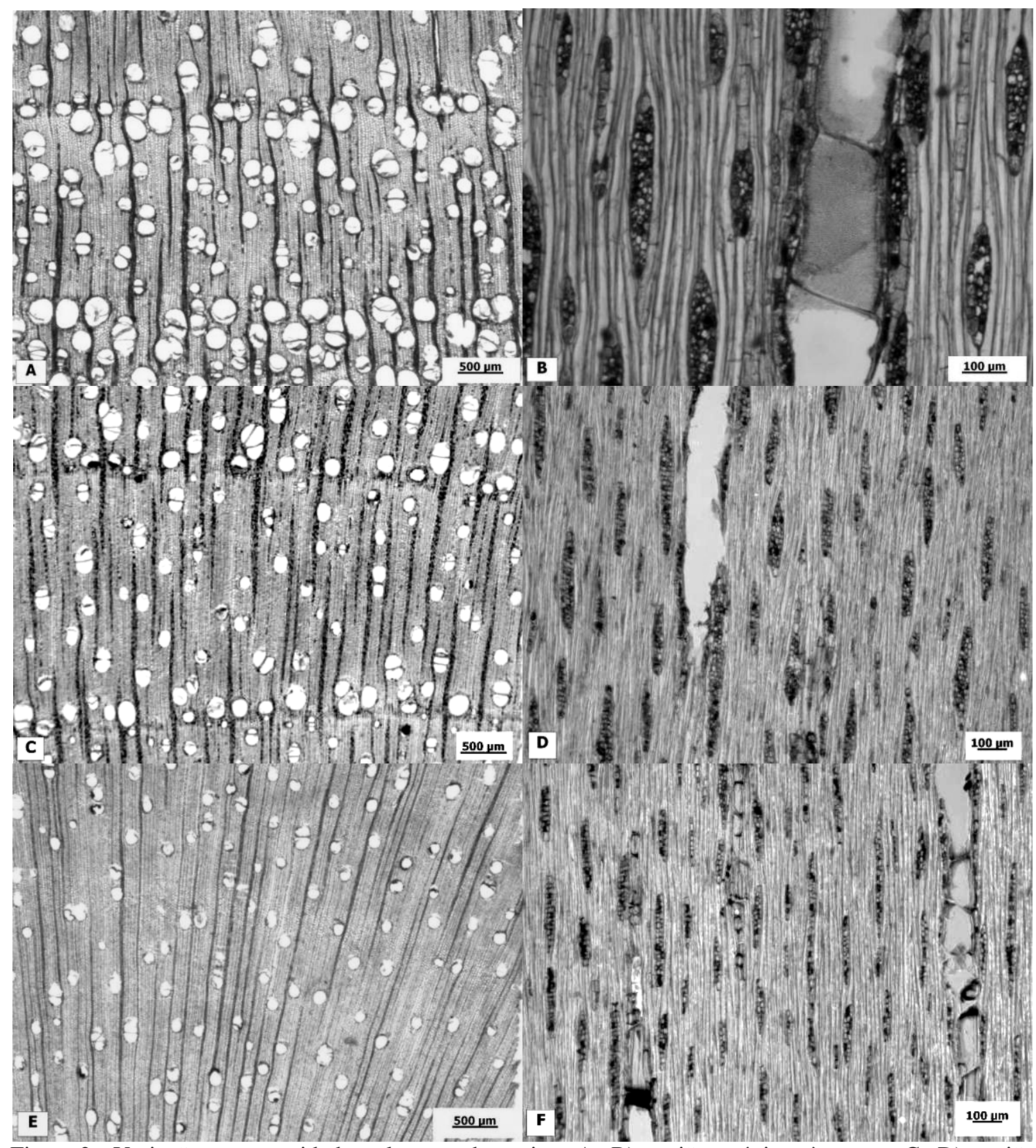

Figura 2. Variação na porosidade e largura dos raios. A, B) região próxima à casca; C, D) região intermediária; $\mathrm{E}, \mathrm{F})$ região próxima à medula.

Figure 2. Porosity and width ray variation. A, B) region near bark; C, D) intermediate region; E, F) region near pith. 


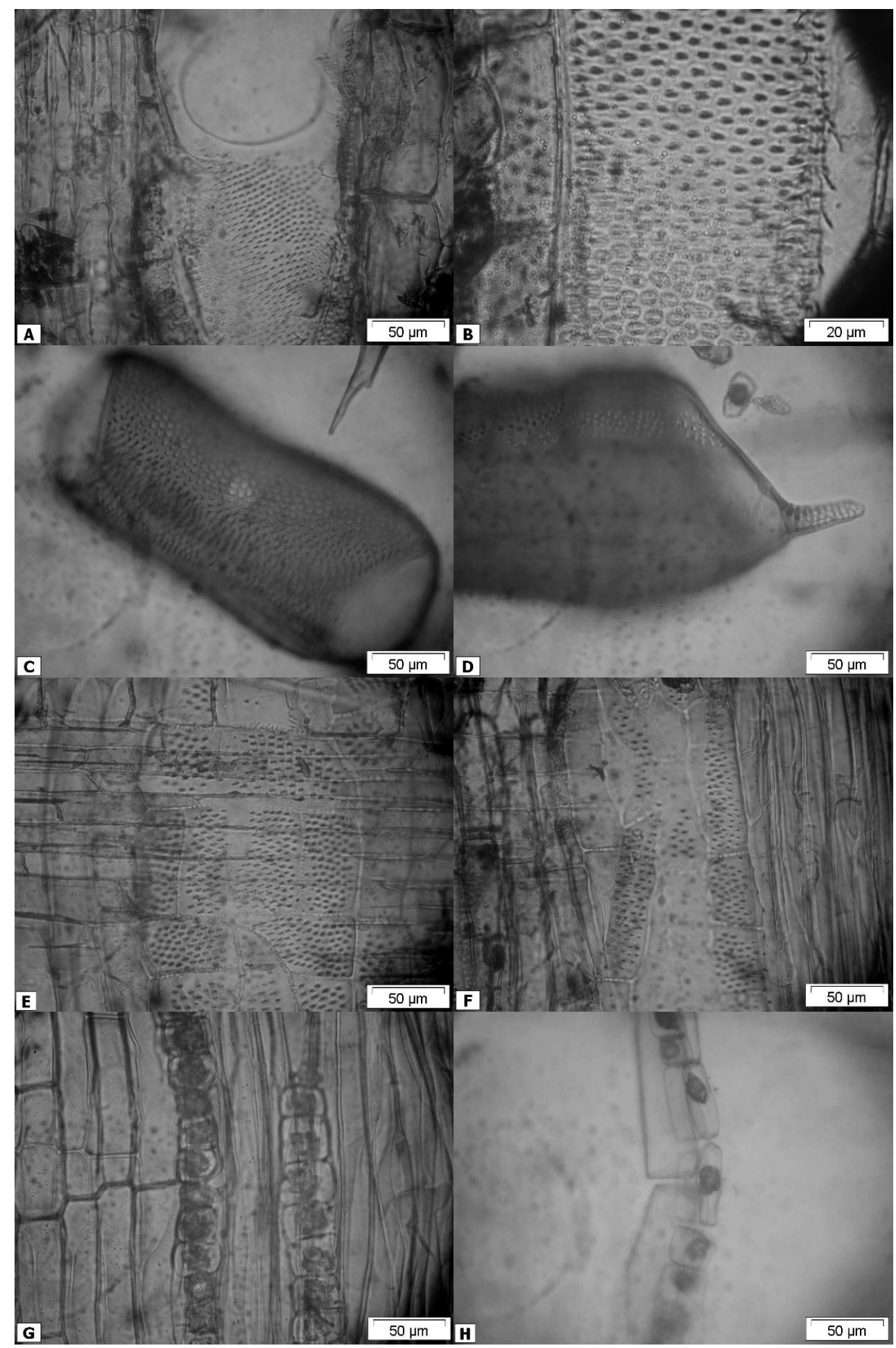

Figura 3. A) placa de perfuração simples; B) pontoações intervasculares; C) elemento de vaso; D) elemento de vaso com apêndice; E) pontoações raio-vasculares; F) pontoações parênquimovasculares; $\mathrm{G}, \mathrm{H}$ ) drusas nas células de parênquima axial.

Figure 3. A) simple perforation plate; B) intervessel pits; C) vessel element; D) vessel element with appendices; E) vessel ray pits; F) parenchyma vessel pits; G, H) druses in axial parenchyma cells. 


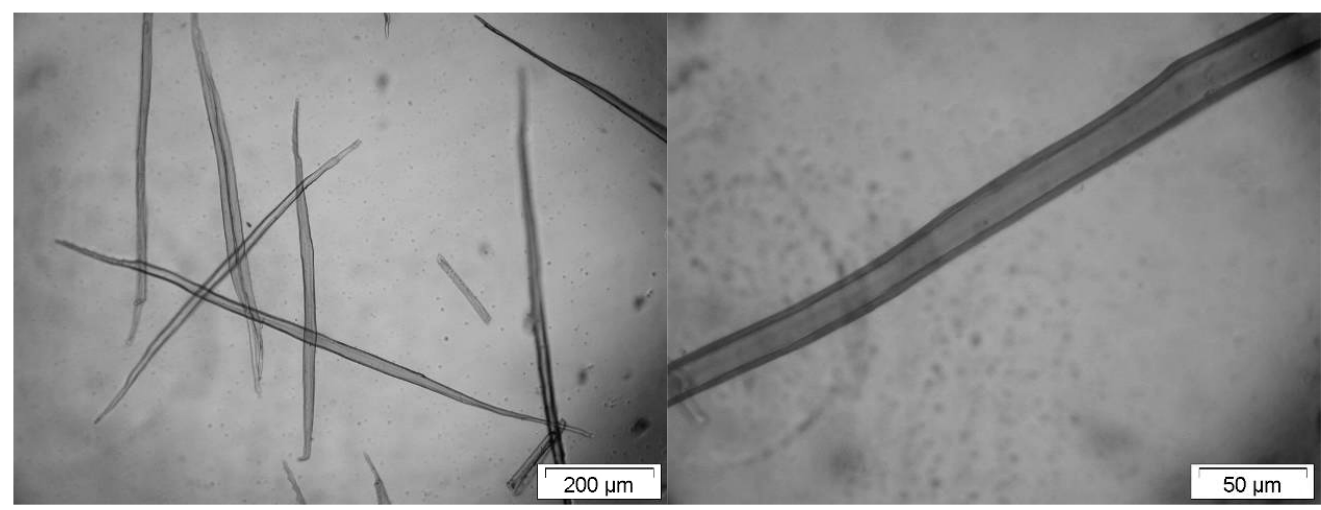

Figura 4. Aspecto geral das fibras.

Figure 4. General fibers aspect.

Os valores médios das dimensões avaliadas na madeira de Toona ciliata são apresentados nas tabelas 1 e 2, e os índices calculados para a avaliação da qualidade da polpa celulósica a ser produzida, na tabela 3, verificando-se a variação radial dos elementos.

Tabela 1. Variação estrutural no sentido medula-casca.

Table 1. Structural variation from pith to bark.

\begin{tabular}{|c|c|c|c|c|c|c|c|c|}
\hline & Posição & $\begin{array}{c}\text { Diâmetro } \\
\text { poros }(\mu \mathrm{m})\end{array}$ & $\begin{array}{c}\text { Raio/mm } \\
\text { (n) }\end{array}$ & $\begin{array}{c}\text { Altura } \\
\text { raios (n) }\end{array}$ & $\begin{array}{l}\text { Largura } \\
\text { raios (n) }\end{array}$ & $\begin{array}{c}\text { Altura } \\
\text { raios }(\mu \mathrm{m})\end{array}$ & $\begin{array}{l}\text { Largura } \\
\text { raios }(\mu \mathrm{m})\end{array}$ & $\begin{array}{c}\text { Poros } / \mathbf{m m}^{2} \\
\text { (n) }\end{array}$ \\
\hline Mínimo & $\mathrm{C}$ & 50,0 & 2,0 & 3,0 & 1,0 & 110,0 & 20,0 & 2,0 \\
\hline Média & & $166,5^{\mathrm{a}}$ & $4,7^{\mathrm{a}}$ & $11,5^{\mathrm{a}}$ & $2,7^{\mathrm{a}}$ & $268,9^{\mathrm{a}}$ & $48,4^{\mathrm{a}}$ & $4,7^{\mathrm{a}}$ \\
\hline Máximo & & 310,0 & 9,0 & 32,0 & 4,0 & 590,0 & 80,0 & 9,5 \\
\hline Desvio & & 58,19 & 1,32 & 5,14 & 1,0 & 76,46 & 14,38 & 1,76 \\
\hline Mínimo & I & 50,0 & 2,0 & 2,0 & 1,0 & 60,0 & 10,0 & 1,0 \\
\hline Média & & $149,6^{\mathrm{b}}$ & $6,1^{\mathrm{b}}$ & $12,6^{\mathrm{ab}}$ & $2,7^{\mathrm{a}}$ & $246,2^{\mathrm{a}}$ & $42,7^{\mathrm{b}}$ & $5,0^{\mathrm{a}}$ \\
\hline Máximo & & 250,0 & 11,0 & 33,0 & 4,0 & 640,0 & 80,0 & 24,0 \\
\hline Desvio & & 45,2 & 1,7 & 5,9 & 0,9 & 93,0 & 14,2 & 2,8 \\
\hline Mínimo & $\mathrm{M}$ & 50,0 & 2,0 & 3,0 & 1,0 & 70,0 & 10,0 & 2,0 \\
\hline Média & & $115,1^{\mathrm{c}}$ & $8,1^{\mathrm{c}}$ & $13,9^{\mathrm{b}}$ & $1,9^{\mathrm{b}}$ & $265,9^{\mathrm{a}}$ & $28,7^{\mathrm{c}}$ & $6,4^{\mathrm{b}}$ \\
\hline Máximo & & 250,0 & 14,0 & 31,0 & 3,0 & 700,0 & 60,0 & 15,0 \\
\hline Desvio & & 29,4 & 2,5 & 5,9 & 0,8 & 121,2 & 9,0 & 2,5 \\
\hline
\end{tabular}

*Médias seguidas pela mesma letra na coluna não diferem entre si pelo teste de Tukey a 95\% de probabilidade. (C: próximo à casca; I: intermediária; M: próximo à medula).

O diâmetro tangencial dos vasos aumentou no sentido medula-casca, característica refletida e corroborada pela variação no número de poros por milímetro quadrado, que diminuiu no sentido medulacasca. Os vasos são considerados como elementos estruturais com a maior capacidade de adaptação às condições ecológicas do sítio, representadas pela disponibilidade de água no solo e pela temperatura em zonas temperadas (BAAS, 1982; ZIMMERMANN, 1982; CARLQUIST, 1989). O aumento do diâmetro dos vasos com o envelhecimento da árvore é considerado uma adaptação anatômica do xilema para incrementar o volume de seiva mineral, aumentando a sua capacidade fotossintética (CARLQUIST, 1989).

A largura dos raios aumentou no sentido medula-casca, sendo que próximo à medula eram mais estreitos, tornando-se mais largos próximos à casca, o que afeta a quantidade de raios por mm, que diminuiu no sentido medula-casca. A altura dos raios teve uma leve mudança em relação ao número de células, mas permaneceu semelhante nas posições na medida em micrometros. As variações no sentido medula-casca dos raios são reportadas como resposta a um decréscimo do nível de auxinas em relação ao aumento da idade das árvores (ALONE; ZIMMERMANN, 1983). Estudos com Eucalyptus grandis (ROCHA et al., 2004), Croton floribundus (ZANON et al., 2008) e Liquidambar styraciflua (ZANON et $a l ., 2009)$, entre outras espécies, também verificam essa variação. As tendências ecológicas relacionadas 
ao tamanho e tipo de raio têm recebido menor atenção devido à dificuldade de interpretação nos vários sistemas ecológicos (BAAS, 1982). Alves e Angyalossy-Alfonso (2000; 2002) determinaram tendências anatômicas para 491 espécies incluídas em 22 famílias, de diferentes ambientes, latitudes e altitudes, e concluíram que a composição dos raios não segue um padrão.

Tabela 2. Comprimento dos elementos de vasos e dimensões das fibras.

Table 2. Vessel element length and fiber dimension.

\begin{tabular}{lcccccc}
\hline & Posição & $\begin{array}{c}\text { Comprimento } \\
\text { vaso }(\mu \mathbf{m})\end{array}$ & $\begin{array}{c}\text { Comprimento } \\
\text { fibra }(\mu \mathbf{m})\end{array}$ & $\begin{array}{c}\text { Largura } \\
\text { fibra }(\mu \mathbf{m})\end{array}$ & $\begin{array}{c}\text { Diâmetro } \\
\text { lume }(\mu \mathbf{m})\end{array}$ & $\begin{array}{c}\text { Espessura } \\
\text { parede }(\mu \mathbf{m})\end{array}$ \\
\hline Mínimo & $\mathrm{C}$ & 190,0 & 570,0 & 20,0 & 10,0 & 5,0 \\
Média & & $409,2^{\mathrm{a}}$ & $1081,9^{\mathrm{a}}$ & $31,5^{\mathrm{a}}$ & $18,4^{\mathrm{a}}$ & $6,6^{\mathrm{a}}$ \\
Máximo & & 590,0 & 1770,0 & 60,0 & 40,0 & 15,0 \\
Desvio & & 80,3 & 206,6 & 7,5 & 7,12 & 2,4 \\
\hline Mínimo & $\mathrm{I}$ & 160,0 & 531,3 & 20,0 & 10,0 & 3,1 \\
Média & & $360,5^{\mathrm{b}}$ & $932,4^{\mathrm{b}}$ & $29,7^{\mathrm{ab}}$ & $16,3^{\mathrm{b}}$ & $6,7^{\mathrm{a}}$ \\
Máximo & & 530,0 & 1400,0 & 50,0 & 37,5 & 10,0 \\
Desvio & & 91,4 & 173,4 & 6,9 & 6,4 & 2,3 \\
\hline Mínimo & $\mathrm{M}$ & 170,0 & 500,0 & 18,8 & 10,0 & 3,1 \\
Média & & $349,2^{\mathrm{b}}$ & $831,6^{\mathrm{c}}$ & $27,8^{\mathrm{b}}$ & $15,1^{\mathrm{ab}}$ & $6,4^{\mathrm{a}}$ \\
Máximo & & 530,0 & 1420,0 & 50,0 & 40,0 & 15,0 \\
Desvio & & 104,7 & 197,0 & 6,7 & 5,9 & 2,3 \\
\hline
\end{tabular}

*Médias seguidas pela mesma letra na coluna não diferem entre si pelo teste de Tukey a 95\% de probabilidade. (C: próximo à casca; I: intermediária; M: próximo à medula).

Os valores médios do comprimento dos elementos de vaso, das fibras, a largura da fibra e diâmetro do lume aumentaram no sentido medula-casca, sendo que a espessura da parede teve uma pequena variação, mas não significativa estatisticamente. O crescimento das árvores provoca variação nas dimensões das células, que tendem a crescer e depois estabilizar na maturidade da árvore. Também as características climáticas e de solo influenciam nas dimensões dos elementos celulares. Alves e Angyalossy-Alfonso (2000; 2002) determinaram tendências anatômicas para espécies de 22 famílias em diferentes ambientes, latitudes e altitudes, e verificaram que fibras de paredes mais espessas ocorrem em menores latitudes e fibras de paredes mais finas em ambientes mais úmidos.

Os valores médios para o comprimento da fibra na região próxima à medula e o diâmetro do lume nas regiões intermediária e próximo à casca são semelhantes aos obtidos para árvores com 4 anos de idade na região de Cana Verde, Campo Belo e Santo Antônio do Amparo, avaliando-se a variação axial do tronco (RIBEIRO et al., 2011), indicando a influência das condições de crescimento além da idade.

Tabela 3. Índices indicativos da qualidade da polpa celulósica.

Table 3. Indicative indices from cellulose pulp quality.

\begin{tabular}{lccccc}
\hline & Posição & $\begin{array}{c}\text { Coeficiente de } \\
\text { flexibilidade }(\%)\end{array}$ & $\begin{array}{c}\text { Fração parede } \\
(\%)\end{array}$ & $\begin{array}{c}\text { Índice de } \\
\text { enfeltramento }\end{array}$ & Índice de Runkel \\
\hline Mínimo & $\mathrm{C}$ & 25,00 & 20,00 & 14,25 & 0,25 \\
Média & & $57,53^{\mathrm{a}}$ & $42,47^{\mathrm{a}}$ & $36,19^{\mathrm{a}}$ & $0,87^{\mathrm{a}}$ \\
Máximo & & 80,00 & 75,00 & 71,00 & 3,00 \\
Desvio & & 13,68 & 13,68 & 10,84 & 0,57 \\
\hline Mínimo & $\mathrm{I}$ & 33,33 & 14,29 & 15,00 & 0,17 \\
Média & & $53,87^{\mathrm{a}}$ & $46,13^{\mathrm{a}}$ & $33,03^{\mathrm{b}}$ & $0,99^{\mathrm{a}}$ \\
Máximo & & 85,71 & 66,67 & 61,00 & 2,00 \\
Desvio & & 13,40 & 13,40 & 9,85 & 0,56 \\
\hline Mínimo & $\mathrm{M}$ & 25,00 & 20,00 & 16,75 & 0,25 \\
Média & & $53,68^{\mathrm{a}}$ & $46,32^{\mathrm{a}}$ & $30,96^{\mathrm{b}}$ & $0,98^{\mathrm{a}}$ \\
Máximo & & 80,00 & 75,00 & 71,00 & 3,00 \\
Desvio & & 12,51 & 12,51 & 8,39 & 0,53 \\
\hline
\end{tabular}

*Médias seguidas pela mesma letra na coluna não diferem entre si pelo teste de Tukey a 95\% de probabilidade. (C: próximo à casca; I: intermediária; M: próximo à medula). 
Apenas o índice de enfeltramento apresentou diferença estatística entre as regiões de análise, sendo que próximo à casca a média foi maior, resultado de um maior comprimento das fibras.

O coeficiente de flexibilidade, relação entre o diâmetro do lume e a largura da fibra, tem relação parabólica com o comprimento de autorruptura (PETERI, 1952), sendo considerado que quanto maior esse coeficiente, melhor a resistência à tensão, uma vez que a fibra é mais flexível, ocorrendo maiores possibilidades de ligações interfibras na folha de papel (FOELKEL; BARRICHELO, 1975; ALMEIDA, 2003). Os valores obtidos para a Toona ciliata indicam que as fibras apresentam colapso parcial, boa superfície de contato e boa união fibra a fibra, sendo inferiores aos observados em estudos de Pinus taeda, com diferentes idades, por Klock (2000), Hassegawa (2003) e Nisgoski (2005), e de clone de Eucalyptus (TRUGILHO et al., 2005), porém um pouco superiores aos do estudo de Cit (2007) com árvores de Pinus taeda aos 16 anos e Eucalyptus dunii aos 10 anos.

A fração parede, considerada como a relação entre o dobro da espessura da parede e o raio da fibra (FOELKEL; BARRICHELO, 1975), indica a rigidez da fibra, sendo esperados valores inferiores a $40 \%$, para que as fibras não sejam extremamente rígidas. Os valores médios deste estudo estão um pouco acima do considerado como ideal e maiores do que os obtidos em estudos de Pinus taeda em diferentes idades (NISGOSKI, 2005) e de clones de Eucalyptus (TRUGILHO et al., 2005), e inferiores aos do estudo de Cit (2007) com árvores de Pinus taeda aos 16 anos e Eucalyptus dunii aos 10 anos.

O índice de enfeltramento, relação entre o comprimento e a largura da fibra, é relacionado com a resistência ao rasgo e arrebentamento (GONZAGA et al., 1983), sendo valores acima de 50 mais indicados para boas características do papel, estando relacionado com o rasgo e dobras duplas (BALDI, 2001). Os resultados para Toona ciliata foram baixos, sendo inferiores aos normalmente encontrados em pínus e eucalipto, o que pode refletir na baixa resistência do papel produzido.

O índice de Runkel, calculado pela relação entre duas vezes a espessura da parede celular e o diâmetro do lume, indica a flexibilidade da fibra, fornecendo uma ideia da capacidade de união das fibras (BALDI, 2001; CAUMO, 2003). Valores próximos a 1, como os obtidos neste estudo, não são desejáveis, uma vez que as fibras se tornam rígidas e com maior dificuldade de acomodação e união na formação da folha de papel. Valores menores para Pinus taeda em diferentes idades foram observados em estudos de Klock (2000), Hassegawa (2003) e Nisgoski (2005), porém Cit (2007) obteve índice de Runkel maior que 1 para Pinus taeda aos 16 anos e Eucalyptus dunii aos 10 anos.

As fibras do cedro-australiano são curtas, com largura e espessura da parede médias (IAWA 1989), e as relações entre suas dimensões não indicam a madeira para a produção de papel para embalagem, podendo ser utilizadas na linha tissue ou para escrita e em misturas com outras espécies. Papéis para impressão ou escrita devem possuir características como lisura, opacidade, imprimibilidade, resistência e estabilidade dimensional, obtidas com numerosas fibras curtas e estreitas, com relativa rigidez e boa refinabilidade, capazes de se manter unidas sem colapsar, constituindo uma rede bem estruturada, com boa ligação entre fibras e baixo teor de elementos de vaso. Papéis da linha tissue, por sua vez, devem apresentar maciez, suavidade ao tato, absorção, sensação de papel fofo e volumoso, resistência e baixo teor de finos, características obtidas com fibras rígidas e com baixo grau de colapsabilidade, para resistir à gofragem e crepagem, além de fibras estreitas, baixo teor de parênquima e baixa ligação entre fibras, mantendo uma rede frouxa e porosa (FOELKEL, 2010), características que a madeira de Toona apresenta.

\section{CONCLUSÕES}

A análise da estrutura anatômica da madeira de Toona ciliata permite concluir que ela apresenta variação, estatisticamente significante em nível de 5\% de probabilidade, nas dimensões dos elementos constituintes no sentido medula-casca, resultado dos diferentes estágios de crescimento da planta. A presença de raios unisseriados e multisseriados, fracamente heterogêneos, placa de perfuração simples, elementos de vaso com e sem apêndice demonstram que a espécie está numa fase intermediária de evolução. Em algumas amostras existem drusas em maior quantidade, indicando a influência das características do solo/adubação no local de plantio. Os valores obtidos para os índices indicativos da qualidade da polpa celulósica não indicam a madeira de Toona ciliata para a produção de papel do tipo embalagem, em que são exigidas boas propriedades de resistência. Recomendam-se estudos para a aplicação da espécie na linha tissue, na qual as características de absorção da folha são mais importantes. 


\section{AGRADECIMENTOS}

Os autores agradecem à Battistella Florestal, pela concessão de uso dos plantios experimentais, ao Prof. Antonio Higa, Coordenador do Projeto FINEP/BATTISTELA/UFPR, e à Financiadora de Estudos e Projetos (FINEP).

\section{REFERÊNCIAS}

ALMEIDA, F. S. Influência da carga alcalina no processo de polpação Lo-Solids® para madeiras de eucalipto. 115 f. Dissertação (Mestrado em Recursos Florestais) - Escola Superior de Agricultura "Luiz de Queiroz", Universidade de São Paulo, Piracicaba, 2003.

ALONE, R.; ZIMMERMANN, M. The control of vessel size and density along the plant axis-a new hypothesis. Differentiation, Saint Paul, v. 24, p. 203 - 208, 1983.

ALVES, E. S.; ANGYALOSSY-ALFONSO, V. Ecological trends in the wood anatomy of some Brazilian species. 1. Growth rings and vessesl. IAWA Journal, Leiden, v. 20, n. 1, p. 3 - 30, 2000.

. Ecological trends in the wood anatomy of some Brazilian species. 2. Axial parenchyma, rays e fibres. IAWA Journal, Leiden, v. 23, n. 4, p. 391 - 418, 2002.

BAAS, P. Systematic, phylogenetic and ecological wood anatomy. In: BAAS, P. New perspectives in wood anatomy: systematic, phylogenetic and ecological wood anatomy. Boston: Martinus Nijhofff/Dr. W.; London: Publishers Junk, 1982. p. 23 - 58.

BALDI, F. Il processo di produzione dele paste chimiche e il loro trattamento. Verona: $8^{\circ}$ Corso di Tecnologia per Tecnici Cartari Edizione 2000/2001. 41 p.

CAMPOS, E. S.; MARTINS, M. A. L.; FOELKEL, C. E. B.; FRIZZO, S. M. B. Seleção de critérios para a especificação de pastas celulósicas branqueadas de eucaliptos na fabricação de papéis para impressão "offset". Ciência Florestal, Santa Maria, v. 10, n. 1, p. 57 - 75, 2000.

CARLQUIST, S. Comparative wood anatomy: systematic ecological, and evolutionary aspects of dicotyledon wood. Berlin: Springer-Verlag, 1989. 436 p.

CAUMO, M. La raffinazione. Verona: $10^{\circ}$ Corso di Tecnologia per Tecnici Cartari Edizione 2002/2003. $47 \mathrm{p}$.

CIT, E. J. Qualidades da folha de polpa kraft em diferentes proporções de Pinus taeda L. e Eucalyptus dunii M. 65 f. Dissertação (Mestrado em Ciências Florestais) - Universidade Federal do Paraná, Curitiba, 2007.

COMISSÃO PANAMERICANA DE NORMAS TÉCNICAS (COPANT). COPANT 458. Maderas Selección y colección de muestras, 1972.

FOELKEL, C. E. B.; BARRICHELO, L. E. G. Relações entre características da madeira e propriedades da celulose e papel. O Papel, São Paulo, v. 36, n. 9, p. 49 - 53, 1975.

FOELKEL, C. Qualidade da madeira de eucalipto para atendimento das exigências do mercado de celulose e papel. Celsius Degree/Grau Celsius. Disponível em: <www.celsofoelkel.com.br/artigos/32\%20final.doc>. Acesso em: 15/12/2010.

GAMBLE, J. S. A manual of indian timbers. Bishen Singh Mahendra Pal Singh, 1972. 868 p.

GIBBS, N. Guia essencial da madeira: um manual ilustrado de 100 madeiras decorativas e suas aplicações. Lisboa: LISMA, 2005. 256 p.

GONZAGA, J. V.; FOELKEL, C. E. B.; BUSNARDO, C. A.; GOMIDE, J. L.; SCHMIDT, C. Qualidade da madeira e da celulose kraft branqueada de treze espécies de Eucalyptus. In: CONGRESSO LATINOAMERICANO DE CELULOSE E PAPEL, 3., 1983, São Paulo. Anais... São Paulo: ABCP, 1983. p. 21 26. 
HASSEGAWA, M. Qualidade da madeira de Pinus taeda L. de procedência da África do Sul. 107 f. Dissertação (Mestrado em Ciências Florestais) - Universidade Federal do Paraná, Curitiba, 2003.

HEINRICH, I.; WEIDNER, K.; HELLE, G.; VOS, H.; LINDESAY, J.; BANKS, J. C. G. Interdecadal modulation of the relationship between ENSO, IPO and precipitation: insights from tree rings in Australia. Clim Dyn, v. 33, p. 63 - 76, 2009.

HEINRICH, I.; BANKS, J. C. G. Tree ring anomalies in Toona ciliata. IAWA Journal, v. 27, n. 2, p. 213 - 231, 2006.

HIDAYAT, S.; SIMPSON, W. T. Use of green moisture content and basic specific gravity to group tropical woods for kiln drying. Res. Note FPL-RN-0263. Madison, WI: U. S. Department of Agriculture, Forest Service, Forest Products Laboratory. 1994. 39 p.

IAWA. List of microscopic features for hardwood identification. IAWA Bulletin, v. 10, n. 3, p. 219 $332,1989$.

KLOCK, U. Qualidade da madeira juvenil de Pinus maximinoi H. E. Moore. 347 f. Tese (Doutorado em Ciências Florestais) - Universidade Federal do Paraná, Curitiba, 2000.

KRAUS, J. E.; ARDUIN, M. Manual básico de métodos em morfologia vegetal. Seropédica, Rio de Janeiro: Editora Universidade Rural, 1997. 198 p.

LAMPRECHT, H. Silvicultura nos trópicos: ecossistemas florestais e respectivas espécies arbóreas possibilidades e métodos de aproveitamento sustentado. Rossdorf: TZ - Verl.- Ges, 1990. 343 p.

LORENZI, H. SOUZA, H. M.; TORRES, M. A. V.; BACHER, L. B. Árvores exóticas no Brasil: madeireiras, ornamentais e aromáticas. Nova Odessa, SP: Instituto Plantarum, 2003. 384 p.

MILANEZ, A. C.; FOELKEL, C. E. B. Processos de deslignificação com oxigênio para a produção de celulose de eucalipto. In: CONGRESSO ANUAL DA ABCP, 14., 1981, São Paulo. Anais... São Paulo: ABTCP, 1981. p. 37 - 110.

MUÑIZ, G. I. B.; CORADIN, V. R. Normas de procedimentos em estudo de anatomia da Madeira. I Angiospermae, II - Gimnospermae. Brasília: Laboratório de Produtos Florestais. Série Técnica 15, 1991.

NISGOSKI, S. Espectroscopia no infravermelho no estudo de características da madeira e papel de Pinus taeda L. 160 p. Tese (Doutorado em Ciências Florestais) - Setor de Ciências Agrárias, Universidade Federal do Paraná, Curitiba, 2005.

NOCK, C. A.; GEIHOFER, D.; GRABNER, M.; BAKER, P. J.; BUNYAVEJCHEWIN, S.; HIETZ, P. Wood density and its radial variation in six canopy tree species differing in shade-tolerance in western Thailand. Annals of Botany, v. 104, n. 2, p. 297 - 306, 2009.

OIANO NETO, J. Estudo fitoquímico de Toona ciliata uma contribuição à quimiossistemática do gênero e à ecologia da interação Hypsipyla Meliaceae. 287 p. Tese (Doutorado em Química) Universidade Federal de São Carlos, São Carlos, 2000.

PAIVA, Y. G.; MENDONÇA, G. S.; SILVA, K. R.; NAPPO, M. E.; CECÍLIO, R. A.; PEZZOPANE, J. E. M. Zoneamento agroecológico de pequena escala para Toona ciliata, Eucalyptus grandis e Eucalyptus urophylla na bacia hidrográfica do rio Itapemirim, ES, utilizando dados SRTM. In: SIMPÓSIO BRASILEIRO DE SENSORIAMENTO REMOTO, 13., 2007, Florianópolis. Anais... Florianópolis: INPE, 2007. p. 1785 - 1792.

PEREYRA, O.; SUIREZS, T. M.; PITSCH, C.; BÁEZ, R. Estudio de las propiedades físico-mecánicas y comportamiento en procesos industriales de la madera de kiri, grevílea, paraíso y toona. Curitiba, FUPEF, Floresta, v. 36, n. 213 - 223, 2006.

PETERI, R. Pulping studies with African tropical woods. TAPPI, v. 35, n. 4, p. 157 - 160, 1952.

RETULAINEN, E.; EBELING, K. Fibre-fibre bonding and ways of characterizing bond strength. Appita, v. 46, n. 4, p. 282 - 288, 1993. 
RIBEIRO, A. de O.; MORI, F. A.; MENDES, L. M. Características das dimensões das fibras e análise do ângulo microfibrilar de Toona ciliata cultivada em diferentes localidades. Floresta, Curitiba, v. 41, n. 1, p. 47 - 56, 2011.

ROCHA, F. T.; FLORSHEIM, S. M. B.; COUTO, H. T. Z. Variação das dimensões dos elementos anatômicos da madeira de árvores de Eucalyptus grandis Hill ex Maiden aos sete anos. Revista do Instituto Florestal, São Paulo, v. 16, n. 1, p. 43 - 55, 2004.

SOLER, M. Mil maderas. Valencia: Universidad Politécnica de Valencia, 2006. 603 p.

STYLES, B. T. The flower biology of the Meliaceae and its bearing on tree breeding. Silvae Genetica v. 21, n. 5 , p. 175 - 182, 1972.

TARNOWSKI, C. G. Propagación agâmica de Toona ciliata var. australis (Meliaceae) mediante açodo em montículo. In: JORNADAS FORESTALES DE ENTRE RIOS, 22., 2007, Concórdia, Argentina. Anais... Concórdia, 2007. p. 1 - 5.

TRIANOSKI, R. Avaliação do potencial de espécies florestais alternativas de rápido crescimento para produção de painéis de madeira aglomerada. $260 \mathrm{f}$. Dissertação (Mestrado em Engenharia Florestal) - Universidade Federal do Paraná, Curitiba, 2010.

TRUGILHO, P. F.; BIANCHI, M. L.; GOMIDE, J. L.; LIMA, J. T.; MENDES, L. M.; MORI, F. A.; GOMES, D. F. F. Clones de Eucalyptus versus a produção de polpa celulósica. Ciência Florestal, Santa Maria, v. 15, n. 2, p. 145 - 155, 2005.

URIAS, J. C. T. Determinación de los índices de calidad de pulpa para papel de 132 maderas latifoliadas. Madera y Bosques, v. 2, n. 2, p. 29 - 41, 1996.

ZANON, B. R.; LONGHI, E. L.; FLORSHEIM, S. M. B.; LIMA, I. L. Variação radial da densidade básica e dimensões celulares de Croton floribundus Spreng. na Serra da Cantareira, SP. In: SEMINÁRIO DE INICIAÇÃO CIENTÍFICA DO INSTITUTO FLORESTAL, 2., 2008, São Paulo. Anais... São Paulo: Instituto Florestal, 2008. p. 25 - 29.

ZANON, B. R.; LIMA, I. L.; LONGHI, E. L.; FLORSHEIM, S. M. B. Variação de algumas propriedades físicas e anatômicas da madeira de Liquidambar styraciflua L. (Sweet gum) em função da posição radial na tora em diferentes classes de diâmetro. IF Sér. Reg., São Paulo, n. 40, p. 69 - 74, 2009.

ZIECH, R. Q. S. Características tecnológicas da madeira de cedro-australiano (Toona ciliata M. Roem) produzida no sul do Estado de Minas Gerais. 91 f. Dissertação (Mestrado em Ciência e Tecnologia da Madeira) - Universidade Federal de Lavras, Lavras, 2008.

ZIMMERMANN, M. Transport in the xylem. In: ZIMMERMANN, M.; BROWN, C. L. Trees structure and function. New York: Springer-Verlag, 1982. 365 p. 
